\title{
Application And Analysis Of Witkey Mode In Network Economy
}

\author{
Liucheng Zhang \\ The practice teaching management center,Harbin University of Commerce,Harbin,China \\ zhangliucheng@126.com
}

Keywords: Witkey mode; Internet economy; Invisible products; Value

\begin{abstract}
Witkey mode in the network economy application of Witkey mode conforms to new ways to now economics of law of value, but also to stimulate the Internet use. The rapid development of the Internet, on all aspects of social development plays a strong role in promoting and depth of penetration. Network economy to flourish in the world, has unlimited potential for development, its definition is widely. We from the micro level of network economics, the development of Witkey mode analysis, defined as the network economy is a market network or large virtual market.With This paper analysed the application of Witkey mode from network economics, and put forward feasible solutions to those problem with low penetration in network economy, vulnerabilities in network security and smal scale in network market.
\end{abstract}

\section{The connotation and significance of Witkey mode}

Witkey mode is using the Internet network innovation model of management of knowledge and information. Since the Witkey mode is put forward, by various scholars and experts from the different angles of Witkey mode profound discussion and research, such as Witkey mode of credit system establishment principle, Witkey mode of wheel web site model, XY theory of Witkey mode, Qin Kai from a legal point of view to explore the Witkey mode -- and planning $>$ of $<$ Internet Witkey mode of legal issues, Zhang Chenming of Witkey mode site a, B, C three categories -- < concern a, B, C type Witkey $>$, Xiao from the point of view of knowledge management study of Witkey Mode ${ }^{[1]}$. By far, the development of Witkey mode is not perfect. From most can manifest the Witkey mode of pig eight quit nets, Witkey business mode, clear, high reliability, but its popularity is not high, it is not wide, there are still many immature place needs to be improved ${ }^{[2]}$.

\section{Application of Witkey mode in network in Economics}

Witkey mode in the network economy application of Witkey mode conforms to new ways to now economics of law of value, but also to stimulate the Internet use. The rapid development of the Internet, on all aspects of social development plays a strong role in promoting and depth of penetration. Network economy to flourish in the world, has unlimited potential for development, its definition is widely ${ }^{[3]}$. We from the micro level of network economics, the development of Witkey mode analysis, defined as the network economy is a market network or large virtual market.

Witkey mode of network economics a reflected, in a certain extent, improve economic efficiency, promote the innovation of science and technology. The popularity of computer and network, people gradually from change the traditional ways of trading for the online transaction. Electronic commerce in our daily life has a great influence on. Application of electronic commerce makes us to stay at home can used the online purchase of products or services. Modern electronic commerce is the trend of industrial development. In the era of information and network, Witkey mode gradually become the life of a new trend ${ }^{[4]}$. The Internet trading not only reduce operating costs, reduce the trading process, optimize the quality of service and Can greatly improve the company's value and visibility, the results generated by the traditional way of trading is difficult to achieve.

Due to the different perspectives of different age classes, Witkey mode based on Internet information sharing to all people to seek knowledge, wisdom, skill, experience, intangible products help to complete the demand side because of a problem stagnant, encounter difficult people as soon as 
possible to find a way to solve the problem, to smoothly perform the next step work. Breaking the breaking the geographical, time, work, through the Internet to workers across the country in the same platform. Provides a wide selection of Internet environment to the labor demand, bring more guidance, ideas and thoughts not only reduce expenditure of publicity costs, reducing May have less environmental pollution, but also enable customers to witness its strength lies. Relative to the working people, professional features more obvious, the relevant professionals to help must be work with high efficiency and high quality, promote the lack of conditions of small and medium-sized enterprise economic development ${ }^{[5]}$. Each person has their own talent and wonderful, it depends on human thinking infinitive. Brain than any of the latest technology products are strong, you can't imagine it's creative potential. In not one hundred percent to help others to complete the work, a creative or is a word of advice for the demand side to bring hundreds of thousands of inspiration, and create outstanding works. To a certain extent, it can improve the economic benefit, promote the economic development, and it also greatly affect the scientific and technological innovation.

\section{Analysis of the current situation of Witkey mode in Network Economics}

Witkey Witkey Witkey and Witkey Witkey is compared at present, Internet penetration rate and the United States, Japan, South Korea and other countries there is still a big gap. From the early manifestation of Witkey mode K68 Witkey network and the most representative pig eight quit nets, development is still unstable. A promotion efforts is not enough, on the other hand is the market scale is small, the transaction is a single cause. According to Metcalfe's law "network value equal to the network node number of square", indicating that the Witkey benefits along with the network user growth is exponential growth. Penetration rate is low the fundamental reason is the lack of utility efficiency and user growth is positively correlated. That is to say, when the user in the Network technology in the utility of the greater, the more get the favour of Witkey users, improve the enthusiasm of the users of the Internet, make it grow faster. Further promote the growth of Witkey benefit, increase rate of penetration, forming a virtuous circle. In turn promotion force shortage problem will with the virtuous cycle solved. When every Witkey users in to the Internet, to a combination of a brain and a computer to create the new intangible products, rich intangible products trading range. On the basis of expanding the demand side economies of scale so as to broaden the market scale.

\section{In the network economy, the improvement strategy of Witkey mode}

To meet the needs of the society, improve the penetration rate of Witkey mode.Original Witkey mode realization of value is the main product knowledge, wisdom, skill and experience, but should used to market the transaction type is mainly the design, planning, and other aspects. This model for the general population is single, narrow trading, application groups namely Witkey fewer households. According to the analysis of the market size in front shall in Witkey mode based on the increased application of the crowd, such as college students, the elderly. For college students can through this platform to exercise their ability to deal with things, more easy to contact with the society, improve their ability of practical operation. Due to the different perspective, the thinking of the students are more active, in the recommended easier creation Thinking, improve work efficiency. Above analysis were adopted to meet the impetus to the popularity of the network economy practical, inexpensive, convenient and technical integration ${ }^{[6]}$. Therefore, by increasing the application of the crowd, to implement the system integration to improve the rate of the popularity of Witkey mode with high probability.

The establishment of information security evaluation system.Information security is the most important information in the information security. Therefore, the establishment of information security evaluation system is an important part of improving the reliability and feasibility of information exchange, and it is necessary to put forward a new kind of intangible product, which can 
be used to produce real utility ${ }^{[7]}$. Otherwise, it is not valuable. The intangible product is unable to trade through the information security evaluation system.

Secondly, Witkey users personal information not another operation. The establishment of information security evaluation system in addition to determine the transaction "commodity", the quality should be Witkey users personal authentication information security ${ }^{[8-10]}$. Witkey mode only bonuses task operation system and profit model even through the full payment, never refund. This leads to a lot of demand side than will have a certain degree of difficulty, to pay the high amount of task release, showing for Witkey mode of trust. If the transaction of every step of the part to achieve evaluation operation, such as in the transaction process difficult add contract system and digital signature, you can greatly reduce mistrust, improve the Witkey Profit model. Again, improve the self management system of Witkey mode. The application of Witkey mode lies in the implementation of the management system, if itself is not enough to support the technical framework of the Witkey mode, its theoretical structure also useless. Finally, Witkey mode and stable development in the foundation will learn organization into organizational innovation, namely in continuous learning based on, the innovation as the first meaning of Witkey platform for survival, promote Witkey platform continuously, create value. Witkey theory is applied in the practical management, to achieve real sense of knowledge value ${ }^{[11]}$.

Combined with the 58 city network increases city trading service system in Witkey mode.For Witkey mode of trade skills, verbal description does not fully complete the task, it is not easy to realize the value of the skills. Therefore, the combination of the 58 city network launched with the city transaction service system is necessary. By solving the drawbacks of simple Witkey mode of pure network transactions through the city exchanges, essentially the problem of demand side, the Witkey mode reflects the value of Witkey mode.Compared with the previously mentioned warmth help " point system, the city services is convinient for those elder people whose children who are not beside,needing life asisstance,can find suitable person to help their organization or good person in the city zone of platform ${ }^{[12]}$. In this way, we have the network of services expended, the living and working efficiency of the crowd improved, so that the solution to the problem becomes simple and smooth.

In addition, the Witkey map ,building by the one of the credit establishenment system to the original Witkey mode, can be through the city services more quickly for realizing the search. Witkey users with problems are able to find professional help in their own city through the witmap. From that, city service trade system in practical reflects the value of Witkey mode.

Also in order to promote the city service for the feasibility of the transaction system of the city, it is recommended to set up agency in a certain region, mete out related agencise. Witkey users who are in charge of a small region must assume that responsibility for the authenticity of customer information, it requires the agent through telephone interview or field study to conduct the feedback. And it is also demand that the both parties of VIP users with a big mount of transaction connect to make sure the reliability of the exchange.

\section{Conclusion}

Under the circumstance of the high development of the Internet, Witkey mode through the Internet will get a brain and a computer together,and will combine the people's wisdom and machine to realize the evaluation of knowledge, causing a huge impact for the economic benefit and social benefit . Analysising the Witkey mode from the perspective of the network economy, information technologywill be accelerated the pace of develpment in the future.And the integration of network enterprises and traditional enterprises will create the worth of the trading environment for the network users trust.We have faith on the Witkey mode that based on the practical construction which can make the Witkey mode application system more perfect, backing to the period of development speed, and create greater value and benefit for the development of network economics and social science and technology. 


\section{Acknowledgement}

This work was financially supported by the National-level Project of College Student's Innovative and Entrepreneurial Training Program,Code of Project: 201410240011.

\section{References}

[1] Feng Liu , Lingling Zhang and Jifa Gu: Knowledge management in the application of the Internet -- Witkey mode in China

[2] Xiaobai Sheng,Yao Han,Di Xu , Dong Wang and Shunguo Deng: Network economics, Electronics Industry Press 2009(11). pp.28-29

[3] The lack of credit in Witkey -- pig network as an example

[4] Li Zhang and Liu Cheng Zhang: Innovative thinking mode of application oriented personnel training to explore the [J]. China's higher education,2012(19). pp.62-63

[5] Li Zhang and Liu Cheng Zhang: The construction and practice of the experimental teaching center of modern enterprise business operations virtual simulation experiment.2014 (11). pp.1-4

[6] Gao Yuan, College students' innovative entrepreneurial training plan of project process management research and exploration [J], Journal of laboratory science, 2013 (6), pp. 71-74.

[7] Yang Weizhi, Using the simulation system to cultivate students ability of enterprise management [J], Journal of laboratory research and exploration, 2013, no. 4, pp. 11-13.

[8] Zhang Li,Applied talents cultivation of innovative thinking mode exploration [J], China's higher education, 2012, (19) , pp.12-13

[9] Chen Yinping, Yin Long, College students' innovative entrepreneurial training plan to carry out the practice and exploration, in Harbin university of commerce, for example [J], Journal of new economy, 2014,(15) , pp. 41-54.

[10]Si Songmen, Zhuang Yale, Thinking about college students' innovative entrepreneurial training program [J], Journal of heilongjiang education (higher education research and evaluation), 2014, (7) , pp. 31-33.

[11]Zhang Liu Cheng, Provincial colleges and universities to carry out innovative Entrepreneurship Education. Chinese e-commerce, vol.6, pp. 92-93, 2013.

[12]Lili Zhang. Innovation and entrepreneurship training programs Practice of Universities. [J]. Times Financial , vol.14, pp. 62-64, 2013. 